\title{
USING A PROJECT ON ASSISTIVE TECHNOLOGY TO TEACH CAD AND RAPID PROTOTYPING
}

\author{
Shalaleh Rismani, Peter Ostafichuk, Carol Jaeger, Jonathan Nakane \\ University of British Columbia \\ ostafichuk@mech.ubc.ca
}

\begin{abstract}
This paper describes a novel approach used in a first year engineering at UBC to teach computer-aided design (CAD) and rapid prototyping as part of a real-world design project. It is centred on the design of an assistive technology device for a real client who is a quadriplegic and has limited use of his hands. Notably, students were able to create their designs in $C A D$ without receiving any formal instruction on the use of the tool. In addition to CAD and rapid prototyping, the project integrated elements of stakeholder engagement, design, decision-making, and communication. By the end of the three-week module, students submitted a technical memorandum recommending their design, and they were able to submit their CAD files for $3 D$ printing and for entry into an inaugural assistive technology design competition.
\end{abstract}

Keywords: Computer-Aided Design (CAD), Rapid prototyping, Assistive technology design, Stakeholder engagement, Team-Based Learning, First year engineering

\section{INTRODUCTION}

This paper describes a module on assistive technology, CAD and rapid prototyping for a first year introduction to engineering course (APSC 100) at the University of British Columbia. An overview of the module and how it fits within the context of the first year engineering course is provided. The module design focused on delivering three main objectives:

- Introducing CAD and rapid prototyping

- Facilitating stakeholder engagement in design

- Developing communication skills

The module was three weeks long and its flow is illustrated in Fig. 1.

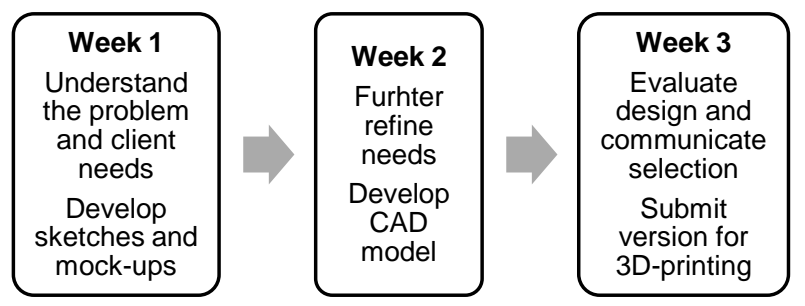

Fig. 1. The module flow by week
Following the module, the students had the option of participating in a design competition to improve their design and communication skills. Results of the design competition and student feedback from the module are discussed. The paper concludes with highlighting some of the major takeaways and lessons learned from development and implementation of this module.

\section{BACKGROUND}

Reviewing the literature indicates two important factors to consider when designing a module for teaching $\mathrm{CAD}$ and rapid prototyping: the process of learning CAD and the interface between the students and the rapid prototyping technologies. There are many examples of how each of these tasks can be done throughout various years; however, we mostly focused on understanding how junior level course, offered in large scales, accomplish this task. There are the two most common ways of teaching CAD software as illustrated in the literature $[2,3,6]$ : detailed tutorial sessions on use of CAD or independent learning through projects. Most courses lean towards creating a structured training component for CAD. The other element to consider is how students interact with the rapid prototyping technologies; students can either use the technologies themselves, or outsource to other vendors $[2,4]$

The APSC 100 course is large (800 students) and is taught in a flipped classroom format with strong elements of Team-Based Learning [1]. Each week in the course has a similar rhythm:

- new topics and basic content are introduced through online video and quiz questions,

- a 1-hour large class (with roughly 200 students) begins with a team quiz based on the online content and then expands upon and begins to apply the content towards a case or project,

- a 2-hour studio (with roughly 60 students) provides teams time to work in detail on their case or project through guided activities, and

- a 1-hr large class reviews and expands on the work of the week, integrating it into a broader context, and looks forward to the week to come.

Each student is individually responsible for the online preparation, but the class, studio, and project work is all team-based, where students work in assigned teams of 56 students.

CEEA17; Paper 122

University of Toronto; June 4-7, 2017 
The course is divided into four modules; this project was the core of the third module. In Module 1, students were introduced the engineering design process, prototyping, and the concept of stakeholders through a cardboard chair project designed for schoolchildren in semi-nomadic communities. Module 2 introduced considerations and strategies for stakeholder consultation and decision-making, with application to a decisionmaking case study for a large infrastructure project.

In Module 3, students combined the elements of the first two modules towards the design and manufacture of an assistive device for a real client. The students selected one of nine areas of possible assistive devices to address a specific need for the client; options included opening a twist-top bottle, holding a guitar pick, or allowing the user to handle small board game pieces. Through prerecorded video, students heard from their client and an occupational therapist; online and in class, they learned about CAD and rapid prototyping; and in class and in their studios they engaged in concept generation, prototyping, and decision-making activities with their team. The generation of the actual CAD files was done individually, out of class time.

\section{MODULE ELEMENTS}

\subsection{Stakeholder Engagement in Design}

Stakeholder engagement was introduced in Modules 1 and 2, and was one of the key themes throughout this module. The two key stakeholders in Module 3 were the client who needed the assistive technology, and the occupational therapist who worked with the client. The stakeholders were real people, and their stories that they shared were also real.

With so many students in the course, it was not possible to give all teams direct access to the client. Instead, a recorded video interview was used, with the occupational therapist interviewing the client. The full interview was 1-hour in length and was provided as a resource to teams, but an abridged 7-minute long version was assigned as required viewing for all students as part of the online preparatory work prior to the first week of the module. In the video, the client talked about the history of his condition and his current challenges, demonstrated his current movement capability, and discussed his day-to-day activities and his existing assistive technologies. To allow some two-way communication and engagement, students had opportunities to pose questions to the client via an online forum on the course learning management system. These questions were reviewed and addressed by the teaching team, the curriculum developer, the occupational therapist, and the client as appropriate.

During the second week of the module, the students were given a 5-minute video from the occupational therapist as part of that week's required online preparation. The occupational therapist described her clinical role and how she uses assistive technology in her practice. She also presented and discussed examples of successful and unsuccessful assistive technologies.

Finally, the students were directed to key resources about 3D-printing and the specific 3D-printing company (Shapeways, https://www.shapeways.com/) used to produce physical prototypes of the APSC 100 projects. Students could direct their questions about the company to the teaching team, who in turn answered them directly or reached out to the company for clarification.

CAD Development and Rapid Prototyping

Students were introduced to CAD software and rapid prototyping in multiple stages. SolidWorks was selected as the CAD package for APSC 100 due to its ease of use, widespread use, and existing license agreements at UBC. In September, in parallel with the first course module, students were given an individual out-of-class assignment to complete the first tutorial integrated into SolidWorks on how to create a CAD part.

In October, in parallel with the second module, students were given a second individual out-of-class assignment to create their own, unique decorative keychain attachment in SolidWorks. Keychains were 3D printed at no cost to students, but were limited in size (maximum $10 \mathrm{~mm} \times 15 \mathrm{~mm} \times 40 \mathrm{~mm}$ ) in order to minimize the overall cost of printing for 800 students (an approximate average price of $\$ 3.50$ USD per part). Parts were commercially SLS printed and returned to students approximately two weeks after files were submitted. Upon return, students had to demonstrate appropriate assembly of their part with a supplied wire keychain loop for full marks (assignment marking was 50\% for submitting a printable CAD file that conformed to the size limits, and $100 \%$ for being able to assemble their part with the wire loop. An example keychain attachment (the white guitar) is shown in Fig. 2, secured to the wire loop. The intent behind this project was twofold: give students additional practice using SolidWorks on a fun and creative project, and demonstrate all stages in the CAD and rapid prototyping process, from conceptual design to $\mathrm{CAD}$, to production prior to the main Module 3 project.

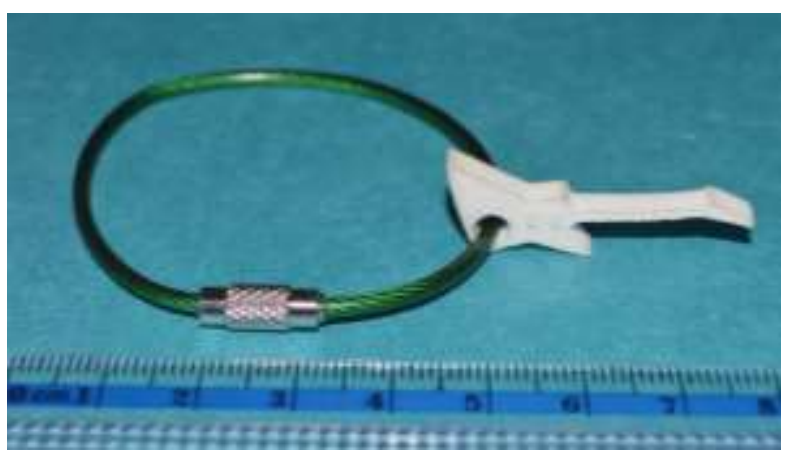

Fig. 2. Sample keychain attachment and wire loop 
In Module 3, the topics of CAD development and rapid prototyping were covered in the online material, lectures, and studios. During the Week 1 classes, students took a more in-depth look at the role of prototyping in the engineering design process and discussed how CAD software can be used effectively. In the Week 1 studio session, teams allowing teams first decided which specific assistive device from the options available they were going to design for. They then worked through a facilitated brainstorming session, which included time with materials for physical prototyping (cardboard, paper, Play-Doh ${ }^{\mathrm{TM}}$ modeling clay, and other similar materials were provided). By the end of the session, students had sketches and digital photographs of their 3D constructions. Each student was instructed to take at least one idea from the studio session and individually create a CAD model from it. Students were expected to prepare CAD models and designs to present to their group in the Week 3 studio session.

In Week 2 of the module, the online material covered the various uses of CAD software beyond 3D modelling. In addition, the students were introduced to three of the most common types of rapid prototyping technologies: 3D-printers, laser jet cutters, and waterjet cutters. The lectures elaborated on various forms of rapid prototyping technologies and students completed an exercise of identifying how various rapid prototyped artifacts were made and why. The students also discussed the best ways of manufacturing of a particular design. There was no studio session during the second week of the module due to the Remembrance Day holiday, but students were tasked with working individually on their CAD files that week. Multiple optional SolidWorks drop-in tutorial sessions were held during this week to support students who needed assistance.

In the Week 3 studio, students brought their individual CAD models (either in the form of CAD files, screenshots, or paper printouts), and, as a team, they use a weighted decision matrix to select one final design to pursue. At the end of the session, a short Design Showcase allowed all students to walk around the room and review all of the team-selected designs in their studio session. At the end of Module 3, all teams were allowed (but not required) to refine this design and submit it for 3D-printing. Students were also encouraged to use these designs as entries in the first year engineering assistive technology design competition (see Section 4.2).

\subsection{Communication Tools}

Module 3 introduced students to multiple communication tools. They were required to prepare an elevator pitch for their individual designs which they shared in their Week 3 studio and design showcase. After choosing a final design, each team needed to provide their design recommendation in the form of a technical memorandum with supporting appendices. The students who chose to participate in the design competition (Section 4.2) needed to create a video pitch.

The online material and the lectures in Week 3 focused heavily on introduction and practice of these communication tools. The online material consisted of two videos. One of the videos introduced the definition of an elevator pitch and a technical memorandum. The videos expanded on the model of audience, purpose, and context by focusing on three elements from the $7 \mathrm{Cs}$ of communication: namely Clear, Concise, and Concrete. (The other four elements from the 7 Cs appeared in the subsequent course module.) The second video of Week 3 was a compilation of interviews from senior engineering students, instructors, and engineers working in the industry about the importance of communication in engineering. The intention was to help the students develop an appreciation for the various communication tools that they are being introduced to them.

\section{MODULE EVALUATION AND OUTCOME}

\subsection{Student Feedback}

An optional survey was conducted at the end of the module and had a response rate of 197 students (roughly $25 \%$ of the cohort). Students were asked about their perception of the effectiveness of the various online videos. Results for the client interview (Week 1) and occupational therapist presentation (Week 2) videos is shown in Fig. 3. In total, $80 \%$ of students identified the client interview video as effective or very effective, compared to $59 \%$ for the occupational therapist video. This may have been because the client was central to the project, and the video featured them and provided a glimpse into their life. In contrast, the occupational therapist was a recorded presentation, more removed from the audience.

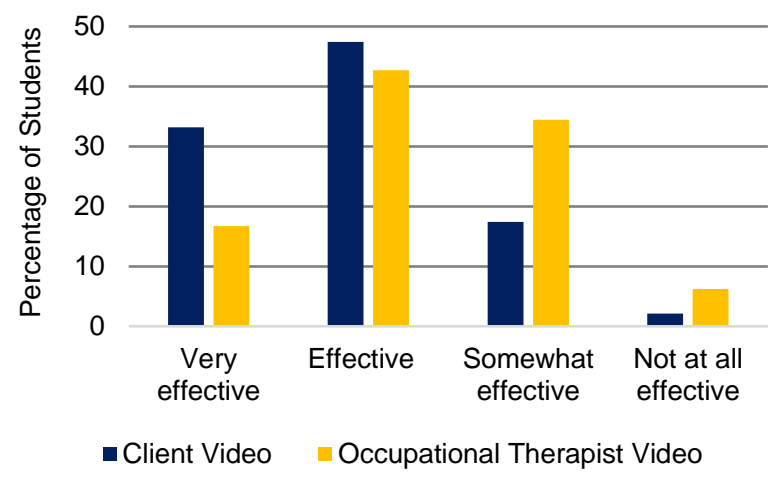

Fig. 3. Effectiveness of the client and occupational therapist online videos 
In the survey, $77 \%$ of respondents agreed that the keychain assignment helped them prepare for the required use of SolidWorks later in the course. On a related question, $50 \%$ of respondents said they were confident or very confident in their ability to use SolidWorks to create a part from sketches or photographs, compared to 35\% who were somewhat confident, and $15 \%$ who were not at all confident (see Fig. 4). This represents an improvement over student responses the previous year, before the keychain exercise was added, where $33 \%$ were confident or very confident, $38 \%$ were somewhat confident, and $29 \%$ were not at all confident.

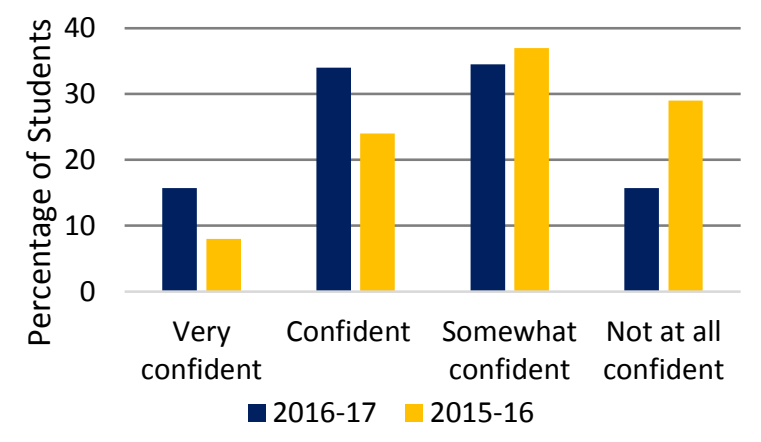

Fig. 4. Confidence creating a CAD model from sketches or photographs

The communication deliverables were challenging for students; however, students also expressed that it is useful to learn these tools. Approximately 59\% and 67\% of students expressed that they were confident or very confident about developing elevator pitches and a technical memo, respectively (see Fig. 5). As shown in Fig. 6, students were also more proud of their technical memo than their pitch. The difference between the technical memo and the elevator pitch might be due to the fact that students had a short period of time to develop their pitch in comparison to their memo. The pitch was also an individual effort, while the technical memo was written as a team.

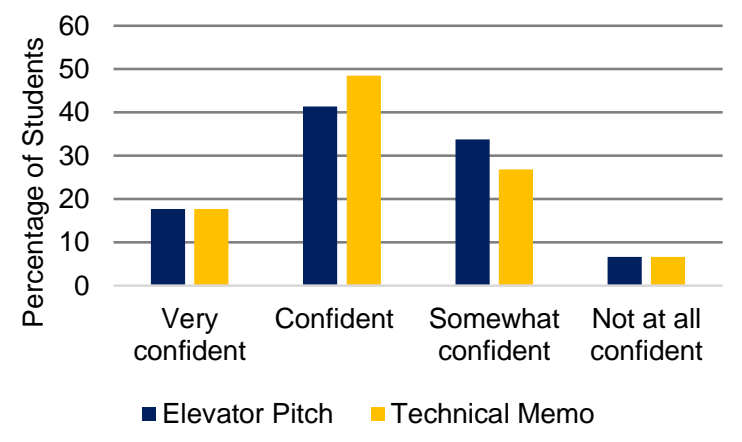

Fig. 5. Confidence creating an elevator pitch and technical memo

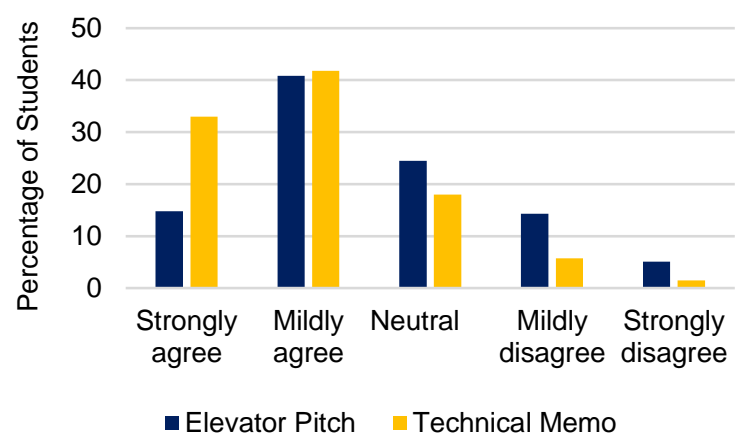

Fig. 6. Percentage agreement with "I was proud of my elevator pitch and technical memo" separately

Overall, $78 \%$ of respondents indicated the project was purposeful and the module was effective in addressing key concepts in assistive technology design, including stakeholder engagement, communication, CAD development, and rapid prototyping.

\subsection{Design Competition}

At the end of the module, teams were invited to participate in an optional design competition. The goal was to create a culminating event for the module and encourage students to 3D print their parts. Interested teams submitted their $\mathrm{CAD}$ file for 3D printing (commercially printed for them, with costs covered by the UBC First Year Engineering program). Once the files were printed and returned to students, teams were given approximately two weeks to prepare and submit a 90second video pitch of their prototype, explaining the context, usage, and benefits of their design. In total, approximately 120 students (16\% of the class) in 30 teams participated in this inaugural competition. All of the submissions were first reviewed and evaluated by two instructors and the module curriculum developer using an evaluation rubric. The rubric consisted of four main evaluation criteria: functionality, ease of use, social acceptance/aesthetics, and professionalism of the video. A shortlist of 10 videos was determined and passed on to a panel of experts in assistive technology including the occupational therapist, a graduate student in biomedical engineering, and a senior biomedical engineering student. The external panel reviewed the shortlisted videos and selected the winning entries using the same rubric outlined above. The two-stage reviewing process led to the selection of the two top teams. The winning design was the "K-pen" (Fig. 7) which is a multi-purpose tool featuring a pen, typing splint, and page-turner. The runner-up is pictured in Fig. 8 (CAD model above and a 3D-printed prototype below), and is a staple remover that is designed to work with limited hand manipulation.

CEEA17; Paper 122

University of Toronto; June 4-7, 2017 


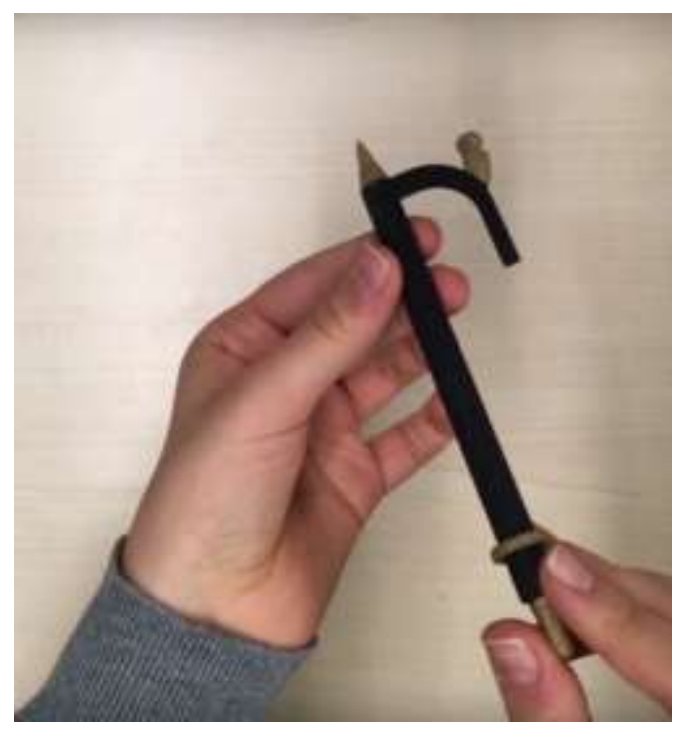

Fig. 7. Winning assistive device design competition entry (“K-pen”)

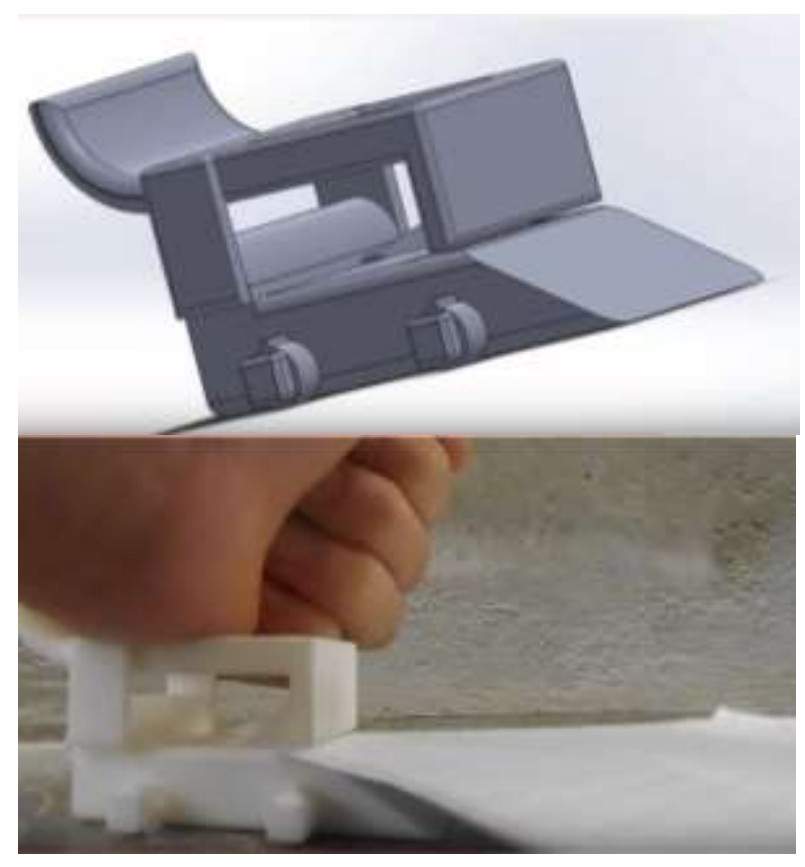

Fig. 8. Runner-up assistive device design competition entry (staple remover)

\section{DISCUSSION AND CONCLUSIONS}

Overall, we feel that this three-week module has successfully introduced students to the use of CAD and rapid prototyping in design, while also enhancing their abilities in conceptual design, stakeholder engagement, and communication.
The student feedback, the interest in participating in the optional competition, and the outcomes of the projects illustrate that students were invested in the module and wanted to deliver a practical solution for their client. The client video played a major role in getting the students to understand the problems that someone with disabilities can face in their lives. We believe it was critical to have an occupational therapist conduct the interview with the client because of their clinical expertise. We also think it was imperative to have a client who was willing, to be honest about their challenges, limitations, and priorities. With the staged introduction of stakeholder input, students needed to continuously consider the input from the relevant person. We believe that it was helpful to have a person with a background in teaching assistive technology, an occupational therapist, and a real client work with us through the two year development of this project. Their insights allow us to create a module that considered multiple stakeholders in its curriculum design which in turn allowed the student teams to consider them in their projects.

Support from the 3D printing services was critical in closing the loop in doing CAD to a final physical product. Few services were able to commit to handling up to 800 individual small-scale objects with a short turn-around time and the ability to individually bag and label each of the pieces. For pre-processing the student-submitted files, we created custom software scripts to ensure that all files were of the allowed size, and nominally met 3D print requirements, as specified by the $3 \mathrm{D}$ printer service.

The primary topic of rapid prototyping was 3D printing, as that was the service used to close the loop in CAD modeling. In future, it may be beneficial to incorporate more from other techniques for rapid prototyping within the course, as several departments on campus have waterjet and laser cutting facilities.

The students expressed that the two communication deliverables: the elevator pitch and the technical memo, were the most challenging component of the module. However, they also noted that they learned how to write a technical memo and deliver an elevator pitch. The way communication was introduced in the module was wellreceived overall. It was helpful to contextualize the importance of communication, and it is important that the course instructors continue to introduce these communication tools in a dynamic way in the lectures.

The entries for the assistive device competition were all universally very good, with high production value and strong communication elements. Participation in the competition was optional, with students awarded prizes for the best two entries for the competition. Based on this success, it may be appropriate to find ways to encourage more students to enter the competition or to have some elements converted into required elements for the course. The timing of the existing competition extended past the end of the APSC 100 course into the next academic term, 
which may prove problematic to integrate it fully into the course for evaluation.

All 30 entries from this year's assistive device competition are now publicly hosted and viewable online (http://tiny.cc/apsc100ATcompetition2017). This is a very good resource and inspiration for our Faculty and course, but may have to be monitored to avoid giving next year's students an advantage if the same topics of assistive devices are used in future course offerings. It may be that developing a longer list of assistive device areas, and rotating them in every few years, is the appropriate direction for the course.

\subsection{Acknowledgements}

We would like to acknowledge Ken Fraser, the client for this module and, Emma Smith, the occupational therapist for their invaluable contributions. We would also like to acknowledge Doug for his advice on designing a module on assistive technology and introducing us to potential clients.

The members of the top winning team were Yas Oloumi, Nima Yazdi and Josh French. The members of the runner-up team were Sari Zerah and Karina Stapleton.

The development of this module was supported by the UBC TLEF Grant.

\subsection{References}

[1] P.M. Ostafichuk, C.P. Jaeger, N. Nakane, S. Nesbit, N. Ellis, J. Sibley, "Redesigning the UBC First Year
Introduction to Engineering: Successes and Challenges," in Proc. of CEEA 2016, 8 pp., Halifax, 2016.

[2] J. Baleshta, P. Teertstra, and B. Luo, "Closing the Loop: Integrating 3D Printing with Engineering Design Graphics for Large Class Sizes," in Proceedings of the Canadian Engineering Education Association, 2015.

[3] C. Laing and S. Balakrishnan, "Integration of Computer Aided Design and Manufacturing at Second Year level in Undergraduate Program," in Proceedings of the Canadian Engineering Education Association, 2011.

[4] B. Nokleby and R. Pop-iliev, "A Design Challenge Incorporating Design into the First Year Engineering Curriculum," in Proceedings of the Canadian Engineering Education Association, 2003.

[5] G. Platanitis and R. Pop-iliev, "Design-Build Project Approach in a First Year Engineering Design Course," in Proceedings of the Canadian Engineering Education Association, 2009.

[6] M. Wlodyka and B. Tomberli, "Incorporating a Community-Based Rapid Manufacturing Facility Into a First Year Engineering Design Course," in Proceedings of the Canadian Engineering Education Association, 2016. 